\title{
AVALIAÇÃO DAS CARACTERÍSTICAS DOS TRABALHADORES DO NÍVEL OPERACIONAL DO SUBSETOR ADMINISTRAÇÃO PÚBLICA DO MUNICÍPIO DE MONTES CLAROS/MG
}

\author{
Renan Zorzy dos Santos Cardoso ${ }^{1}$ \\ Éder de Souza Beirãoº \\ Roney Versiani Sindeaux ${ }^{3}$ \\ Simone Viana Duarte ${ }^{4}$
}

RESUMO: O presente artigo tem como objetivo analisar as características dos trabalhadores do nível operacional do subsetor Administração Pública do município de Montes Claros/MG. O tipo de pesquisa utilizado no estudo foi a descritiva e bibliográfica, assumindo a forma de um estudo de caso do mercado de trabalho do municipio de Montes Claros/MG. Possui abordagem quantitativa de dados, tendo esses sido extraidos por meio de levantamento na Relação anual de Informações Sociais (RAIS), banco de dados disponibilizado pelo Ministério do Trabalho e Emprego (MTE) e do Instituto Brasileiro de Geografia e Estatística (IBGE). Os trabalhadores desse subsetor em sua maior parte estão localizados no Grupo 3 representados pelos trabalhadores com ensino superior, tendo sua maior representatividade na faixa etária dos 40 a 49 anos e recebendo em média cerca de 1 a 2 salários mínimos. As mulheres representam média de $58.19 \%$ do total habitantes do município, sendo responsáveis, possuindo um maior percentual de escolaridade, em relação aos homens do município. Porém, as maiores faixas salariais pertencem aos homens, em detrimento das mulheres. Este cenário representa as desigualdades do mercado de trabalho local e servem de modelo, para que sejam identificadas as dificuldades existente em todo o Brasil.

Palavras-Chave: Mercado de Trabalho; Subsetor Administração Pública; Montes Claros.

ABSTRACT: The objective of this article is to analyze the characteristics of the workers at the operational level of the subsector Public Administration of the municipality of Montes Claros / MG. The type of research used in the study was descriptive and bibliographical, taking the form of a case study of the labor market of the municipality of Montes Claros / MG. It has a quantitative data approach, which has been extracted by means of a survey in the Annual Social Information Relation (RAIS), a database made available by the Ministry of Labor and Employment (MTE)

\footnotetext{
${ }^{1}$ Graduado em Administração pela Universidade Estadual de Montes Claros. E-mail: renanzorzy@gmail.com.

2 Mestrando em Desenvolvimento Social pela Universidade Estadual de Montes Claros. E-mail: ederbeirao@gmail.com.

3 Doutor em Economia pela Universidade Federal de Minas Gerais (UFMG) e professor do Departamento de Ciências da Administração da Universidade Estadual de Montes Claros (UNIMONTES). E-mail: roneyvs@yahoo.com

${ }^{4}$ Mestre em Administração pela Universidade Federal de Minas Gerais (UFMG) e professora no Departamento de Ciências da Administração da Universidade Estadual de Montes Claros (UNIMONTES). E-mail: simonevianaduarte@yahoo.com
} 
and the Brazilian Institute of Geography and Statistics (IBGE). The majority of the workers in this subsector are located in Group 3, represented by workers with higher education, with the highest representation in the age group 40-49 and receiving on average about 1 to 2 minimum wages. The women represent an average of $58.19 \%$ of the total inhabitants of the municipality, being responsible, having a higher percentage of schooling, in relation to the men of the municipality. However, the highest wage rates belong to men, to the detriment of women. This scenario represents the inequalities of the local labor market and serves as a model, so that the difficulties existing in Brazil can be identified.

Keywords: Job market; Subsetor Public Administration; Montes Claros.

\section{INTRODUÇÃO}

O mundo do trabalho vem sendo constantemente analisado sob diversos aspectos devido a suas transformações proporcionadas pela globalização. A mudança da forma organizacional do trabalho introduzida pelo Modelo Toyota de Produção, na década de 1970, dá um novo direcionamento às relações de trabalho, que são mantidas, intensificadas e diversificadas nas suas modalidades, no decorrer dos anos.

Com estas transformações, Antunes (2003) afirma que é possível constatar uma significativa heterogeneização, complexificação e fragmentação do trabalho, provocando diminuição da mão-de-obra empregada na indústria, concomitantemente ao surgimento de novas atividades relacionadas principalmente ao setor de serviços.

Essa fragmentação do trabalho é evidenciada pela teoria da segmentação.

Os defensores da teoria da segmentação, abordam que o mercado não é um único espaço competitivo em que todos os postos de trabalho estariam igualmente disponíveis a todos os trabalhadores, mas sim um conjunto de segmentos que não competem entre si, porém remuneram de formas diferentes o capital humano, porque existem barreiras que não permitem que todos se beneficiem igualmente do mesmo nível de educação e treinamento. Havendo assim um mercado interno no qual os trabalhadores estariam mais protegidos e com melhores condições de trabalho e de qualificação, e um mercado externo, onde o trabalho seria regido de acordo com as regras da economia clássica (OLIVEIRA; PUCCININI, 2011).

Dentre os vários segmentos do mercado de trabalho existe o setor de serviços. Os serviços têm ganhado cada vez mais importância e hoje estão no centro da atividade econômica em todos os países. 
Segundo Cobra (1986), um serviço é qualquer ato ou desempenho que uma parte pode oferecer a outra e que seja essencialmente intangível e não resulta na propriedade de nada. Sua produção pode ou não estar vinculada a um produto físico.

Conforme Kotler (1994) "serviço é uma mercadoria comercializável isoladamente, ou seja, um produto intangível que não se pega, geralmente não se experimenta antes da compra".

A prestação de serviços caracteriza-se por ser intangível, intransferível, não estocável, existindo somente durante o processo produtivo. É composta por um amplo leque de atividades (comércio, transportes, comunicações, instituições financeiras, serviços prestados às famílias, serviços prestados ás empresas, aluguel de imóveis, administração pública e serviços privados não-mercantis), que demonstram a heterogeneidade da composição do setor. De suas características e de sua composição, decorrem os diferentes graus de utilização de capital e trabalho, que tem por resultado uma diversidade de formas de relações de trabalho no setor.

Diante da crescente importância do setor de serviços na estrutura econômica das nações, considera-se relevante fazer uma análise histórica de como a Economia enquanto ciência tem tratado as questões relacionadas a este setor produtivo, uma vez que as atividades terciárias têm influenciando direta e indiretamente o produto e a riqueza das economias desenvolvidas e em desenvolvimento.

Não obstante, analisar o setor terciário da economia não se constitui em uma tarefa fácil, pois a teoria econômica apresenta um corpo analítico amplo apenas para as evidências do comportamento dos setores primário e secundário, o que implica dizer que não se verifica a existência de um quadro teórico global que permita obter uma definição, classificação e mensuração satisfatória do lugar ocupado pelos serviços na dinâmica do capitalismo contemporâneo, bem como no processo de acumulação como um todo.

Inserido na divisão das atividades econômicas do terceiro setor (setor de serviços) da Classificação Nacional de Atividades Econômicas (CNAE), encontra-se - Subsetor da Administração Pública.

O setor institucional administração pública é constituído por unidades que têm como função principal produzir serviços não-mercantis destinados à coletividade e/ou efetuar operações de repartição de renda e de patrimônio. Os serviços são considerados não-mercantis quando prestados a preços economicamente não 
significativos. A principal fonte de recursos do setor é o pagamento obrigatório efetuado pelas demais unidades institucionais na forma de impostos, taxas e contribuições sociais.

Sendo assim, o estudo tem como questão-norteadora: qual é o perfil dos trabalhadores do nível operacional do subsetor Administração Pública do município de Montes Claros/MG?

Este estudo tem como objetivo geral analisar as características dos trabalhadores do nível operacional do subsetor Administração Pública do município de Montes Claros/MG. A fim de alcançar o objetivo geral do estudo, foram traçados os seguintes objetivos específicos: (1) analisar os dados do mercado de trabalho do subsetor Administração Pública do município de Montes Claros/MG; (2) apresentar conceitos e classificações de mercado de trabalho, setor de serviços e subsetor Administração Pública; (3) Discorrer sobre escolaridade (grau de instrução), representatividade de gênero, faixa etária e faixa salarial dos trabalhadores do município de Montes Claros/MG; e (4) descrever o subsetor Administração Pública do município de Montes Claros/MG.

A importância deste trabalho refere-se à observação das transformações ocorridas e o cenário do mercado de trabalho no subsetor de Administração Pública do município de Montes Claros/MG.

A pesquisa está inserida em um Projeto Integrado Interinstitucional (UNIMONTES), intitulado "Mercado de Trabalho e Gestão". O artigo apresenta resultados parciais sobre o trabalhador em nível operacional do subsetor administração pública.

\section{REFERENCIAL TEÓRICO}

\subsection{Teoria da Segmentação}

Oliveira e Puccinini (2011) afirmam o seguinte acerca da teoria da segmentação:

Os defensores da teoria da segmentação, abordam que o mercado não é um único espaço competitivo em que todos os postos de trabalho estariam igualmente disponíveis a todos os trabalhadores, mas sim um conjunto de segmentos que não competem entre si, porém remuneram de formas diferentes o capital humano, porque existem barreiras que não permitem que todos se beneficiem igualmente do mesmo nível de educação e treinamento. Havendo assim um mercado interno no qual os trabalhadores estariam mais protegidos e com melhores condições de trabalho e de qualificação, e um mercado externo, onde o trabalho seria regido de acordo com as regras da economia clássica (OLIVEIRA; PUCCININI, 2011). 
A empresa vive em um ambiente de informação incompleta e de mudança, esta precisa se adaptar à incerteza e à instabilidade e organizar o trabalho em consequência. Esta lógica geral de gestão de mão de obra contém dois aspectos que a princípio são contraditórios: a necessidade de aprovisionamento do trabalho ao menor custo possível e a vontade de aumentar a eficácia do trabalho. Estas duas práticas conduzem para caminhos distintos, por consequência darão origem a formas diferentes de gestão de mão de obra (GAMBIER; VERNIERES, 1991).

Ainda segundo esta teoria, há múltiplos mercados de trabalho que se formam a partir da diversidade de atividades profissionais, podendo haver abundância de demanda em alguns segmentos e setores e falta em outros. Além da profissão, a localização geográfica dos empregos e da mão de obra, os graus de qualificação exigidos, as delimitações etárias multiplicam o número de mercados de trabalhos que se justapõem. Essa pluralidade explica por que, mesmo em um período de desemprego importante, pode ocorrer a ausência de mão de obra em determinados segmentos.

A teoria da segmentação diz que não há somente a existência de sub mercados agindo independentes uns dos outros e funcionando em circuito fechado, mas, que este tipo de segmentação está no centro do mecanismo de funcionamento do mercado de trabalho (CUNHA, 1979).

Segundo Cunha (1979), entre as múltiplas abordagens da segmentação, a ideia de dualidade do mercado de trabalho teve destaque em estudos latinoamericano"

Segundo esta perspectiva, no mercado de trabalho existiria um setor primário (ou central) caracterizado pela segurança da carreira, com procedimentos sociais regulados pelo Estado; e um setor secundário (ou periférico), caracterizado por baixos salários, alta rotatividade de trabalhadores, falta de qualificação, possibilidades restritas de promoção e ausência de segurança no emprego. Este segmento, nitidamente desfavorecido, é formado por trabalhadores em situação de fraqueza junto aos empregadores: trabalhadores imigrantes, mulheres, mão de obra pouco qualificada, trabalhadores de empresas subcontratadas, entre outros.

Depois de apresentar os principais conceitos ligados a teoria da segmentação, o setor de serviços foi o escolhido para ser abordado, mais precisamente o subsetor Administração Pública. O próximo tópico aborda o setor de serviços. 


\subsection{O Setor Serviços}

Nos países que tiveram sua economia baseada em indústrias, a preocupação voltada unicamente para o aumento da produtividade já não atende aos novos requisitos no cenário competitivo atual. Esta é verdadeiramente a Era dos Serviços, a transição de uma economia baseada na fabricação para uma economia baseada no serviço (ALBRECHT, 2000).

Mauad e Pamplona (2002) também colocam que os serviços estão no centro da atividade econômica em todos os países. Fitzsimmons e Fitzsimmons (2000) afirmam que nos anos 90 a economia deixou de ser predominantemente de manufatura, passando para o setor de serviços.

A importância do setor de serviço dos mais variados ramos vem aumentando de importância a cada dia com a urbanização das populações, a introdução de novas tecnologias e o aumento da qualidade de vida.

Afrontando a importância dos serviços e das atividades industriais na atividade econômica, encontra-se uma necessidade de sistemas de apuração de custos nas empresas prestadoras de serviços. A prestação de serviço se apoia em trabalho humano, e os custos de produção variam, pois são definidos subjetivamente por quem o produz (COBRA, 1986).

Grõnroos (1995) explica as três razões para o crescimento do setor de serviços observado durante as últimas décadas: (1) O decrescimento do volume de mão-de-obra requerido para produzir qualquer bem ou serviço; (2) Demanda de procura por empresas especializadas em serviços profissionais; e (3) O crescimento direto na demanda por serviços por parte dos fornecedores.

O conceito de serviço acentuado e defendido por diversos autores. Kotler (1994) define serviço como: "um serviço é qualquer ato ou desempenho que uma parte pode oferecer a outra e que seja essencialmente intangível e não resulta na propriedade de nada. Sua produção pode ou não estar vinculada a um produto físico".

Cobra (1986) define serviço sendo uma mercadoria comercializável isoladamente, ou seja, um produto intangível que não se pega, geralmente não se experimenta antes da compra. 


\subsection{Subsetor de Administração Pública}

O setor institucional administração pública é constituído por unidades que têm como função principal produzir serviços não-mercantis destinados à coletividade e/ou efetuar operações de repartição de renda e de patrimônio. Os serviços são considerados não-mercantis quando prestados a preços economicamente não significativos. A principal fonte de recursos do setor é o pagamento obrigatório efetuado pelas demais unidades institucionais na forma de impostos, taxas e contribuições sociais.

O Manual de Contas Nacionais, também conhecido como System of National Accounts - SNA (1993) aponta que a abrangencia do subsetor administração pública é composto pelas seguintes unidades institucionais:

- $\quad$ Entidades públicas juridicamente constituídas como empresas com funções típicas de governo e cujos recursos são provenientes, em sua maior parte, de transferências;

- Entidades para-estatais que têm como principal fonte de receita recursos tributários vinculados arrecadados pelo governo, são elas:

- Sistema S - instituições produtoras de serviços sociais que têm como principal fonte de receita recursos tributários vinculados arrecadados pelo governo.

- Conselhos Profissionais - instituições de apoio à regulação das atividades profissionais que têm como principal fonte de recursos contribuições compulsórias.

- Fundos de caráter público, como os fundos constitucionais e o FGTS - Fundo de garantia por Tempo de Serviço e PIS/PASEP - Programa de Integração Social e Programa de Formação do Patrimônio do Servidor Público.

- Órgãos governamentais da administração central e entidades descentralizadas (autarquias, fundações e fundos), nos âmbitos federal, estadual e municipal.

\section{METODOLOGIA}

O tipo de pesquisa utilizado na pesquisa do presente artigo tem a finalidade descritiva. Segundo Cervo, Bervian e Silva (2007), "pesquisa descritiva é aquela que ocorre quando se registra, analisa e correlaciona fatos ou fenômenos, sem manipulá-los podendo assumir diversas formas como: estudos descritivos, pesquisa de opinião, pesquisa de motivação e estudo de caso". 
Sua abordagem é quantitativa. De acordo com Richardson (1999), "o método quantitativo caracteriza-se pelo emprego da quantificação, tanto nas modalidades de coleta de informações, quanto no tratamento dessas através de técnicas estatísticas, desde as mais simples, como percentual, média, desvio-padrão, às mais complexas como coeficiente de correlação e análise de regressão".

O método de pesquisa utilizado é o estudo de caso que conforme Gil (2002) "consiste no estudo profundo e exaustivo de um ou poucos objetos, de maneira que permita seu amplo e detalhado conhecimento, tarefa praticamente impossivel mediante outros delineamentos ja considerados".

$O$ instrumento de coleta de dados utilizado foi o levantamento dos dados quantitativos da Relação anual de Informações Sociais (RAIS), banco de dados disponibilizado pelo Ministério do Trabalho e Emprego (MTE) e do Instituto Brasileiro de Geografia e Estatística (IBGE).

A metodologia do trabalho também de utilizou da pesquisa bibliográfica e documental, obtendo resultado através da utilização de artigos científicos, monografias, tese de doutorado, portal eletrônico do RAIS/CAGED, do MTE, relatórios de pesquisa, obras referenciais, dentre outros.

\section{ANÁLISE E DICUSSÃO DE RESULTADOS}

O estudo das características dos trabalhadores do nível operacional do Subsetor Administração Pública do município de Montes Claros/MG é realizado levando-se em consideração o grau de instrução, a faixa etária e a faixa salarial dos mesmos.

A Tabela 01 apresenta a representatividade do grau de instrução do total de trabalhadores ocupados no subsetor Administração Pública entre os anos de 2002 e 2011.

Tabela 01 - Representatividade do grau de instrução do total de trabalhadores ocupados no subsetor Administração Pública entre os anos de 2002 e 2011 (\%)

\begin{tabular}{c|cccccccccc}
\hline Grupos & $\mathbf{2 0 0 2}$ & $\mathbf{2 0 0 3}$ & $\mathbf{2 0 0 4}$ & $\mathbf{2 0 0 5}$ & $\mathbf{2 0 0 6}$ & $\mathbf{2 0 0 7}$ & $\mathbf{2 0 0 8}$ & $\mathbf{2 0 0 9}$ & $\mathbf{2 0 1 0}$ & $\mathbf{2 0 1 1}$ \\
\hline I & 26,34 & 22,60 & 1,97 & 1,64 & 0,81 & 0,90 & 0,98 & 1,42 & 2,13 & 2,16 \\
\hline II & 52,81 & 55,52 & 11,85 & 13,47 & 16,11 & 20,81 & 27,49 & 31,91 & 33,06 & 33,68 \\
\hline III & 20,85 & 21,88 & 86,18 & 84,89 & 83,08 & 78,29 & 71,53 & 66,67 & 64,81 & 64,16 \\
\hline IV & 0,00 & 0,00 & 0,00 & 0,00 & 0,00 & 0,00 & 0,00 & 0,00 & 0,00 & 0,00 \\
\hline Total & 100 & 100 & 100 & 100 & 100 & 100 & 100 & 100 & 100 & 100
\end{tabular}

Fonte: RAIS/CAGED, 2011

Observação: Grupo 1- Ensino Fundamental, Grupo 2- Ensino Médio, Grupo 3- Ensino Superior, Grupo 4- Não classificados. 
Por meio da série histórica de dados fornecidos pela Relação anual de Informações Sociais (RAIS), observa-se que no início do horizonte temporal estudado, ano de 2002, o grau de instrução predominante no subsetor Administração Pública era do Grupo 2 (ensino médio) com 52,81\%, seguido do Grupo 1 (ensino fundamental) com $26,34 \%$. No final do período estudado, pode-se destacar que houve uma significativa mudança no cenário deste subsetor, sendo que o Grupo 3 (ensino superior) se torna o de maior representatividade com $64,16 \%$ do total de vínculos empregatícios. Em 2002, o Grupo 3 representava apenas $20,85 \%$ dos vínculos.

No período analisado o Grupo 1 (ensino fundamental) tem média de representatividade de $6,10 \%$, o Grupo 2 (ensino médio) média de 29,67\%, o Grupo 3 (ensino superior) uma média de $64,23 \%$ e o Grupo 4 (não determinado) média de $0,00 \%$. Isso significa dizer, que a maioria dos vínculos empregatícios firmados no subsetor administração pública é formado por pessoas com alto grau de instrução (aqueles que possuem diploma de curso superior).

A Tabela 02 mostra a representatividade da escolaridade das mulheres no subsetor Administração Pública do município de Montes Claros/MG entre os anos de 2002 e 2011.

Tabela 02 - Escolaridade das mulheres no subsetor Administração Pública do município de Montes Claros/MG entre os anos de 2002 e 2011.

\begin{tabular}{c|cccccccccc}
\hline Grupo & $\mathbf{2 0 0 2}$ & $\mathbf{2 0 0 3}$ & $\mathbf{2 0 0 4}$ & $\mathbf{2 0 0 5}$ & $\mathbf{2 0 0 6}$ & $\mathbf{2 0 0 7}$ & $\mathbf{2 0 0 8}$ & $\mathbf{2 0 0 9}$ & $\mathbf{2 0 1 0}$ & $\mathbf{2 0 1 1}$ \\
\hline I & 12,83 & 10,12 & 1,08 & 0,89 & 0,31 & 0,33 & 0,41 & 0,56 & 0,63 & 0,54 \\
\hline II & 33,53 & 32,59 & 6,47 & 6,62 & 6,63 & 9,64 & 13,38 & 17,07 & 16,47 & 16,21 \\
\hline III & 12,05 & 12,48 & 53,02 & 49,35 & 49,34 & 47,69 & 47,21 & 41,93 & 41,35 & 41,10 \\
\hline IV & 0,00 & 0,00 & 0,00 & 0,00 & 0,00 & 0,00 & 0,00 & 0,00 & 0,00 & 0,00 \\
\hline Total & 58,41 & 55,19 & 60,58 & 56,86 & 56,28 & 57,66 & 61,00 & 59,56 & 58,46 & 57,85 \\
\hline
\end{tabular}

Fonte: RAIS/CAGED, 2011.

Acerca da escolaridade das mulheres que possuem vínculo empregatício no subsetor Administração Pública é possível destacar que entre os anos de 2003 e 2004 a participação do Grupo 3 salta de 12,48\% para 53,02\%, ou seja, empregados de nível operacional do setor se qualificaram, aumentando assim seus níveis de instrução. Observa-se também que neste mesmo período impactado pelo aumento da escolaridade, o Grupo 1 e 2 sofrem uma significativa redução, caindo de 10,12\% para $1,08 \%$ e $32,59 \%$ em 2003 para 6,47\%, respectivamente. A partir do ano de 
2005, o Grupo 2 voltou a crescer, alcançando uma representatividade de $16,21 \%$ em 2011.

A Tabela 03 apresenta a escolaridade dos homens no subsetor Administração Pública do município de Montes Claros/MG entre os anos de 2002 e 2011.

Tabela 03 - Escolaridade dos homens no subsetor Administração Pública do município de Montes Claros/MG entre os anos de 2002 e 2011 (\%)

\begin{tabular}{c|cccccccccc}
\hline $\begin{array}{c}\text { Grupo/ } \\
\text { Anos }\end{array}$ & $\mathbf{2 0 0 2}$ & $\mathbf{2 0 0 3}$ & $\mathbf{2 0 0 4}$ & $\mathbf{2 0 0 5}$ & $\mathbf{2 0 0 6}$ & $\mathbf{2 0 0 7}$ & $\mathbf{2 0 0 8}$ & $\mathbf{2 0 0 9}$ & $\mathbf{2 0 1 0}$ & $\mathbf{2 0 1 1}$ \\
\hline I & 13,51 & 12,48 & 0,89 & 0,75 & 0,50 & 0,57 & 0,57 & 0,86 & 1,50 & 1,62 \\
\hline II & 19,28 & 22,93 & 5,38 & 6,85 & 9,47 & 11,17 & 14,11 & 14,84 & 16,59 & 17,48 \\
\hline III & 8,80 & 9,40 & 33,16 & 35,54 & 33,75 & 30,60 & 24,31 & 24,73 & 23,46 & 23,06 \\
\hline IV & 0,00 & 0,00 & 0,00 & 0,00 & 0,00 & 0,00 & 0,00 & 0,00 & 0,00 & 0,00 \\
\hline Total & 41,59 & 44,81 & 39,42 & 43,14 & 43,72 & 42,34 & 39,00 & 40,44 & 41,54 & 42,15 \\
\hline
\end{tabular}

Fonte: RAIS/CAGED, 2011.

A participação dos homens é maior no Grupo 3. Nota-se que nos anos de 2003 para 2004 houve uma queda brusca da participação dos homens do Grupo 2, tendo uma redução do percentual caindo de $22,93 \%$ para 5,38\%. Em contrapartida, houve um aumento da representatividade dos homens neste mesmo período no Grupo 3, saindo de $9,04 \%$ para $33,16 \%$ do total de trabalhadores do subsetor Administração Pública.

O Gráfico 01 apresenta a escolaridade dos trabalhadores do sexo masculino e feminino no subsetor Administração Pública do município de Montes Claros/MG entre os anos de 2002 e 2011.

Gráfico 01 - Escolaridade dos trabalhadores do sexo masculino e feminino no subsetor Administração Pública do município de Montes Claros/MG entre os anos de 2002 a 2011

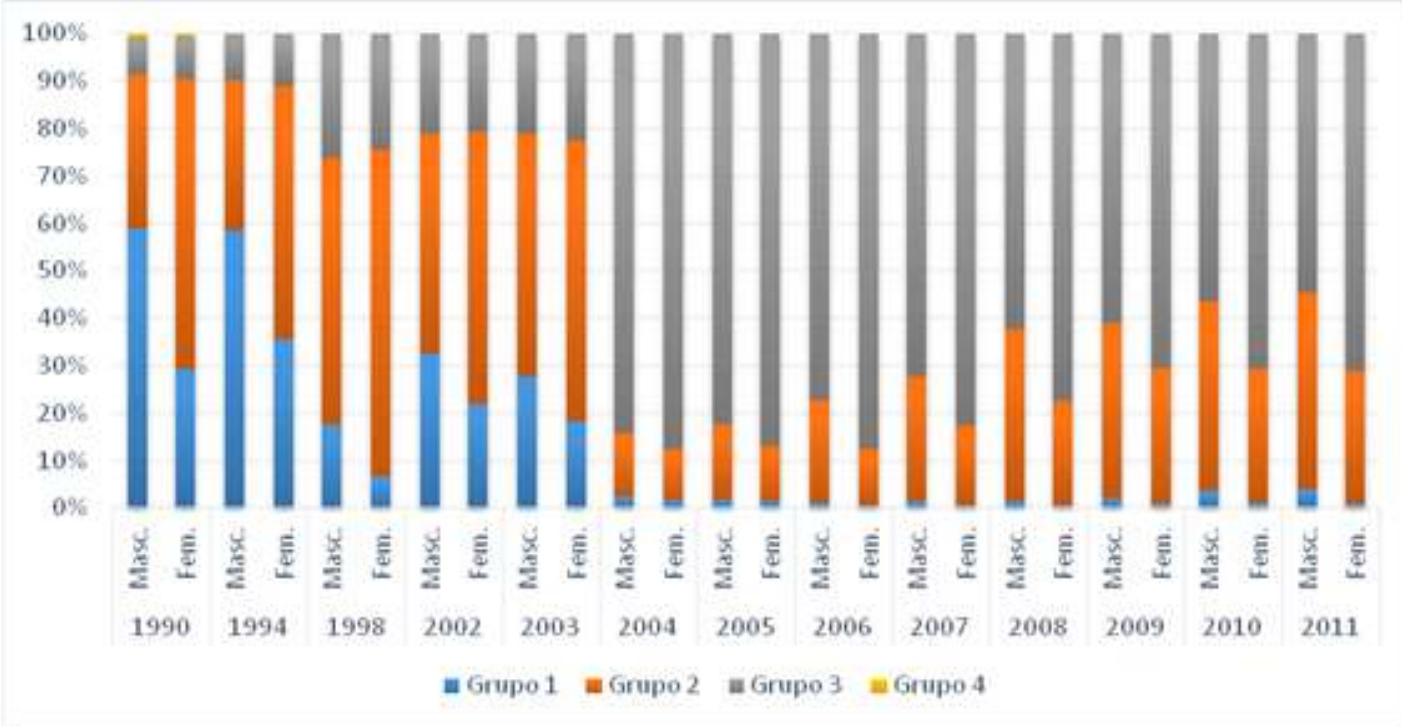

Fonte: RAIS/CAGED, 2011

Observação: Grupo 1- Ensino Fundamental, Grupo 2- Ensino Médio, Grupo 3- Ensino Superior, Grupo 4- Não classificados. 
A participação das mulheres no subsetor Administração Pública cresceu ao longo dos anos. A partir do ano de 2002 o Grupo 3 passou a ter uma maior representatividade das mulheres, mostrando que as mulheres possuem maior escolaridade que os homens neste subsetor.

Nota-se também que este subsetor até o ano de 2003 caracterizava-se por sua diversificação no grau de instrução, a partir de 2004 o Grupo predominante no subsetor foi o Grupo 3, seguido pelo Grupo 2, e havendo uma queda da participação do Grupo 1 e 2.

Isso demonstra que houve uma mudança no grau de instrução dos trabalhadores do subsetor Administração Pública, que no início era composto por trabalhadores que possuíam em sua maioria o ensino fundamental. Este espaço foi sendo ocupado por aqueles trabalhadores que fazem parte do Grupo 3.

A Tabela 04 apresenta a representatividade da faixa etária do total de trabalhadores ocupados no subsetor Administração Pública do município de Montes Claros/MG entre os anos de 2002 e 2011.

Tabela 04 - Representatividade da faixa etária do total de trabalhadores ocupados no subsetor Administração Pública do município de Montes Claros/MG entre os anos de 2002 e 2011 (\%)

\begin{tabular}{c|cccccccccc}
\hline $\begin{array}{c}\text { Faixa } \\
\text { Etária }\end{array}$ & $\mathbf{2 0 0 2}$ & $\mathbf{2 0 0 3}$ & $\mathbf{2 0 0 4}$ & $\mathbf{2 0 0 5}$ & $\mathbf{2 0 0 6}$ & $\mathbf{2 0 0 7}$ & $\mathbf{2 0 0 8}$ & $\mathbf{2 0 0 9}$ & $\mathbf{2 0 1 0}$ & $\mathbf{2 0 1 1}$ \\
\hline $\mathbf{1 8}$ a $\mathbf{2 4}$ & 6,13 & 5,57 & 4,56 & 5,67 & 8,11 & 7,38 & 6,25 & 6,29 & 5,68 & 6,20 \\
\hline $\mathbf{2 5}$ a $\mathbf{2 9}$ & 11,07 & 9,22 & 9,13 & 9,99 & 10,71 & 11,90 & 11,76 & 12,41 & 11,20 & 11,83 \\
\hline $\mathbf{3 0}$ a $\mathbf{3 9}$ & 36,68 & 34,17 & 32,95 & 30,80 & 29,12 & 29,37 & 28,67 & 28,23 & 27,42 & 26,84 \\
\hline $\mathbf{4 0}$ a $\mathbf{4 9}$ & 28,39 & 30,73 & 31,58 & 31,63 & 30,26 & 30,12 & 31,24 & 30,21 & 31,67 & 30,92 \\
\hline $\mathbf{5 0}$ a $\mathbf{6 4}$ & 16,56 & 19,16 & 20,89 & 20,90 & 20,86 & 20,31 & 21,10 & 21,25 & 22,33 & 22,30 \\
\hline $\mathbf{2} \mathbf{6 5}$ & 1,06 & 1,14 & 0,89 & 1,00 & 0,92 & 0,92 & 0,98 & 1,61 & 1,70 & 1,91 \\
\hline \{n class. & 0,10 & 0,00 & 0,00 & 0,01 & 0,01 & 0,00 & 0,00 & 0,00 & 0,00 & 0,00 \\
\hline Total & 100 & 100 & 100 & 100 & 100 & 100 & 100 & 100 & 100 & 100
\end{tabular}

Fonte: RAIS/CAGED, 2011.

No ano de 2002, o subsetor Administração Pública obteve uma maior participação na faixa de 30 a 39 anos, com 36,68\% do total de trabalhadores, seguido da faixa de 40 a 49 anos sendo $28,39 \%$ do total. Sabe-se que a faixa de menor representatividade é a de 65 anos ou mais com 1,06\% do total dos trabalhadores e a faixa de 18 a 24 com $6,13 \%$ do total.

Ao longo dos anos o cenário deste subsetor em relação a faixa etária não teve grandes transformações, só a partir de 2005 a faixa etária de 40 a 49 anos supera ocupando $1^{\circ}$ posição do subsetor Administração Pública obtendo 30,92\% no ano de 2011 contra $26,84 \%$ da faixa de 30 a 39 anos. 
Renan Zorzy dos Santos Cardoso; Éder de Souza Beirão; Roney Versiani Sindeaux; Simone Viana Duarte.

A faixa etária de 18 a 24 anos e a de 65 anos ou mais obteve significativo crescimento neste período, passando a ter representatividades de 6,20\% e 1,91\%, respectivamente no ano de 2011.

A Tabela 05 apresenta a faixa etária das mulheres no subsetor Administração Pública do município de Montes Claros/MG entre os anos de 2002 e 2011.

TABELA 5 - Faixa Etária das mulheres no subsetor Administração Pública do município de Montes Claros/MG entre os anos de 2002 e 2011 (\%)

\begin{tabular}{c|cccccccccc}
\hline $\begin{array}{c}\text { Faixa } \\
\text { Etária }\end{array}$ & $\mathbf{2 0 0 2}$ & $\mathbf{2 0 0 3}$ & $\mathbf{2 0 0 4}$ & $\mathbf{2 0 0 5}$ & $\mathbf{2 0 0 6}$ & $\mathbf{2 0 0 7}$ & $\mathbf{2 0 0 8}$ & $\mathbf{2 0 0 9}$ & $\mathbf{2 0 1 0}$ & $\mathbf{2 0 1 1}$ \\
\hline $\mathbf{1 8}$ a 24 & 2,72 & 1,90 & 2,11 & 2,07 & 3,61 & 3,36 & 3,39 & 3,42 & 3,07 & 3,06 \\
\hline $\mathbf{2 5}$ a 29 & 5,91 & 3,87 & 4,80 & 4,72 & 5,25 & 6,57 & 6,70 & 7,27 & 6,23 & 6,82 \\
\hline $\mathbf{3 0}$ a $\mathbf{3 9}$ & 23,61 & 20,96 & 21,66 & 18,72 & 17,04 & 17,48 & 17,78 & 17,18 & 16,12 & 15,50 \\
\hline $\mathbf{4 0}$ a 49 & 17,80 & 18,75 & 20,57 & 20,06 & 19,18 & 19,27 & 21,06 & 19,89 & 20,66 & 20,18 \\
\hline $\mathbf{5 0}$ a $\mathbf{6 4}$ & 8,16 & 9,51 & 11,23 & 11,02 & 10,95 & 10,67 & 11,72 & 11,28 & 11,84 & 11,70 \\
\hline $\mathbf{2} \mathbf{6 5}$ & 0,18 & 0,20 & 0,21 & 0,25 & 0,25 & 0,31 & 0,35 & 0,52 & 0,53 & 0,59 \\
\hline \{n class. & 0,03 & 0,00 & 0,00 & 0,01 & 0,01 & 0,00 & 0,00 & 0,00 & 0,00 & 0,00 \\
\hline Total & 58,41 & 55,19 & 60,58 & 56,86 & 56,28 & 57,66 & 61,00 & 59,56 & 58,46 & 57,85 \\
\hline
\end{tabular}

Fonte: RAIS/CAGED, 2011.

A faixa etária de maior representatividade das mulheres deste subsetor no ano de 2002 foi dos 40 a 49 anos com $17,80 \%$ do total de trabalhadores ocupados. Este cenário não se modificou no ano de 2011, possuindo ainda a maior representatividade, com $20,18 \%$ do total. Destaque também deve ser dado a faixa etária de 50 a 64 anos que cresceu de 8,16\% (2002) para 11,79\%.

A Tabela 06 apresenta a faixa etária dos homens no subsetor Administração Pública do município de Montes Claros/MG entre os anos de 2002 e 2011.

Tabela 06 - Faixa Etária dos homens no subsetor Administração Pública entre os anos de 2002 e $2011(\%)$

\begin{tabular}{ccccccccccc}
\hline Faixa Etária & $\mathbf{2 0 0 2}$ & $\mathbf{2 0 0 3}$ & $\mathbf{2 0 0 4}$ & $\mathbf{2 0 0 5}$ & $\mathbf{2 0 0 6}$ & $\mathbf{2 0 0 7}$ & $\mathbf{2 0 0 8}$ & $\mathbf{2 0 0 9}$ & $\mathbf{2 0 1 0}$ & $\mathbf{2 0 1 1}$ \\
\hline $\mathbf{1 8}$ a 24 & 3,42 & 3,67 & 2,45 & 3,60 & 4,51 & 4,02 & 2,86 & 2,87 & 2,61 & 3,13 \\
\hline $\mathbf{2 5}$ a 29 & 5,16 & 5,35 & 4,32 & 5,27 & 5,47 & 5,33 & 5,06 & 5,14 & 4,96 & 5,01 \\
\hline $\mathbf{3 0}$ a $\mathbf{3 9}$ & 13,07 & 13,21 & 11,29 & 12,08 & 12,09 & 11,89 & 10,89 & 11,05 & 11,29 & 11,35 \\
\hline $\mathbf{4 0}$ a $\mathbf{4 9}$ & 10,59 & 11,98 & 11,02 & 11,56 & 11,08 & 10,85 & 10,17 & 10,32 & 11,02 & 10,74 \\
\hline $\mathbf{5 0}$ a $\mathbf{6 4}$ & 8,41 & 9,65 & 9,66 & 9,88 & 9,91 & 9,64 & 9,39 & 9,97 & 10,49 & 10,60 \\
\hline $\mathbf{2} \mathbf{6 5}$ & 0,87 & 0,94 & 0,68 & 0,75 & 0,66 & 0,61 & 0,63 & 1,09 & 1,17 & 1,32 \\
\hline \{ class.\} & 0,08 & 0,00 & 0,00 & 0,00 & 0,00 & 0,00 & 0,00 & 0,00 & 0,00 & 0,00 \\
\hline Total & 41,59 & 44,81 & 39,42 & 43,14 & 43,72 & 42,34 & 39,00 & 40,44 & 41,54 & 42,15
\end{tabular}

Fonte: RAIS/CAGED, 2011.

Com os homens não foi diferente. No ano de 2002 sua faixa etária de maior participação no setor foi a de 30 a 39 , com $13,07 \%$ do total de trabalhadores 
ocupados. A situação permaneceu a mesma até meados de 2011, tendo continuado a ser a faixa de maior representatividade no subsetor Administração Pública, com $11,35 \%$. Nota-se que a mesma sofreu uma leve queda de $1,72 \%$. Ou seja, na atualidade, as mulheres no subsetor Administração Pública em sua maioria, são mais velhas do que os homens neste subsetor.

O Gráfico 02 apresenta a representatividade da faixa etária do total de trabalhadores masculinos e femininos ocupados no subsetor Administração Pública do município de Montes Claros/MG entre os anos de 2002 e 2011.

Gráfico 02 - Representatividade da faixa etária do total de trabalhadores masculinos e femininos ocupados no subsetor Administração Pública do município de Montes Claros/MG entre os anos de 2002 e 2011

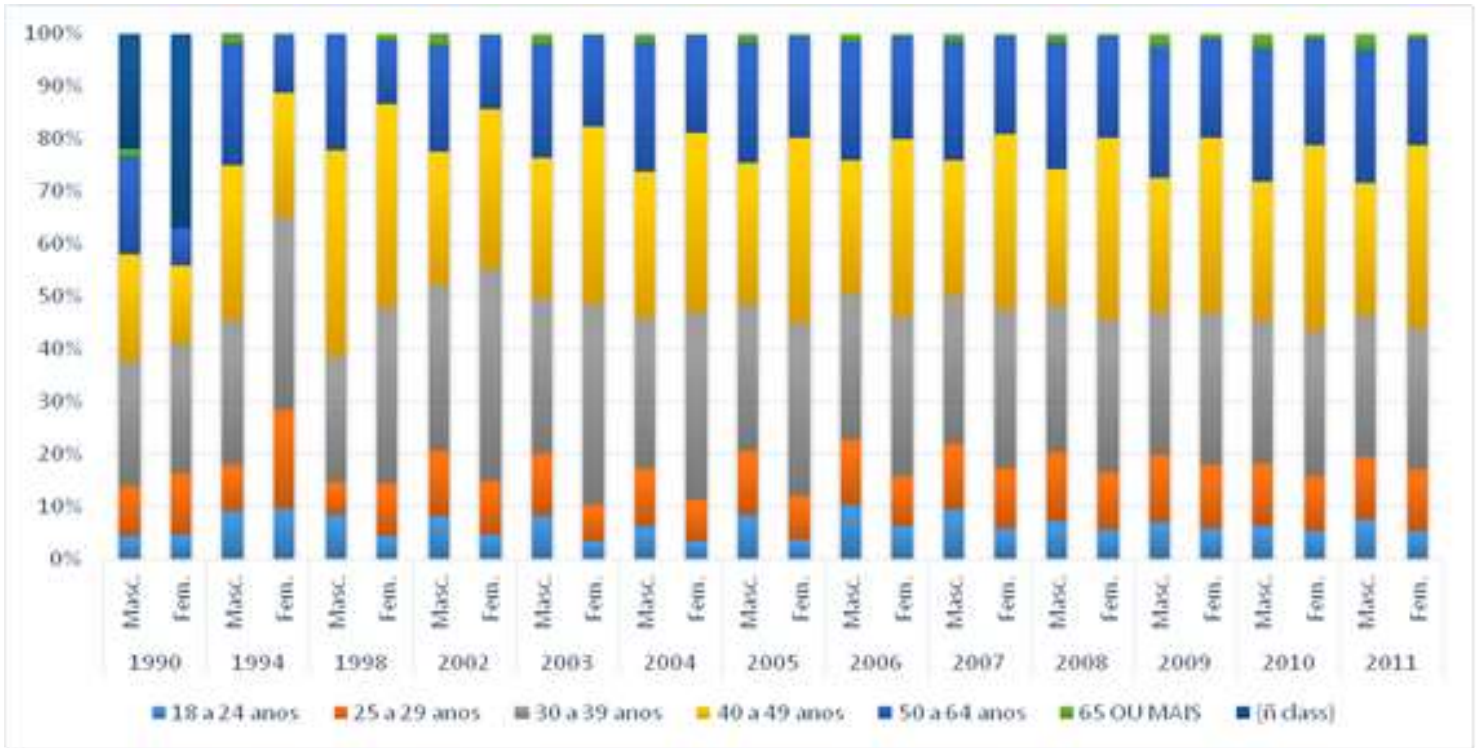

Fonte: RAIS/CAGED, 2011.

A Tabela 07 apresenta a faixa salarial do total de trabalhadores ocupados no subsetor Administração Pública do município de Montes Claros/MG entre os anos de 2002 e 2011.

No subsetor Administração Pública no ano de 2002, a faixa salarial de maior representatividade era a de 1 a 2 salários mínimos com $45,66 \%$, do total de trabalhadores ocupados no subsetor, seguido da faixa de 2 a 5 salários mínimos com $39,11 \%$ do total. Nos anos seguintes estas duas faixas de salário permanecem como as duas de maior participação no subsetor. Observa-se que a faixa e 1 a 2 salários mínimos obteve um aumento ao longo dos anos chegando a $61,36 \% \mathrm{em}$ 2006, embora com ligeira redução, ao final de 2011 esta faixa ainda representa o maior número de trabalhadores com $51,01 \%$. As idades entre 2 a 5 salários 
Renan Zorzy dos Santos Cardoso; Éder de Souza Beirão; Roney Versiani Sindeaux; Simone Viana Duarte.

mínimos obteve um percentual de $36,96 \%$ se posicionando como a segunda faixa salarial mais representativa no ano de 2011.

Tabela 07 - Faixa Salarial do total de trabalhadores ocupados no subsetor Administração Pública entre os anos de 2002 e 2011 (\%)

\begin{tabular}{|c|c|c|c|c|c|c|c|c|c|c|}
\hline $\begin{array}{c}\text { Faixa } \\
\text { Salarial }\end{array}$ & 2002 & 2003 & 2004 & 2005 & 2006 & 2007 & 2008 & 2009 & 2010 & 2011 \\
\hline 0,5 a 1 & 1,25 & 2,31 & 0,42 & 0,76 & 2,48 & 2,48 & 3,50 & 3,65 & 3,12 & 3,48 \\
\hline 1 a 2 & 45,66 & 52,89 & 51,11 & 53,16 & 61,36 & 59,37 & 55,58 & 50,76 & 56,88 & 51,01 \\
\hline 2 a 5 & 39,11 & 34,70 & 35,11 & 29,39 & 26,34 & 27,92 & 32,75 & 36,47 & 31,64 & 36,93 \\
\hline 5 a 10 & 10,18 & 5,78 & 8,81 & 11,80 & 6,37 & 7,14 & 5,28 & 5,52 & 4,93 & 4,85 \\
\hline 10 a 20 & 2,34 & 2,46 & 2,94 & 3,75 & 1,83 & 1,67 & 1,44 & 2,33 & 1,94 & 2,20 \\
\hline + de 20 & 1,36 & 1,34 & 1,51 & 1,07 & 0,38 & 0,33 & 0,29 & 0,33 & 0,22 & 0,33 \\
\hline$\{\tilde{\mathbf{N}}$ class. $\}$ & 0,10 & 0,51 & 0,10 & 0,07 & 1,23 & 1,09 & 1,15 & 0,94 & 1,28 & 1,20 \\
\hline Total & 100 & 100 & 100 & 100 & 100 & 100 & 100 & 100 & 100 & 100 \\
\hline
\end{tabular}

Fonte: RAIS/CAGED, 2011.

É possível perceber que as faixas de menor participação são as de 5 a 10 e de 10 a 20 salários mínimos, nos anos de 2002, apresentaram representatividade de 2,34\% e 1,36\%, respectivamente, e perderam participação no total de trabalhadores do subsetor Administração Pública, passando a apresentar participação de 2,20\% e 0,33\%, respectivamente. Aqueles trabalhadores que recebem mais de 20 salários mínimos representavam $0,10 \%$ do total de trabalhadores em 2002 e passaram a representar em 2011, 1,20\% do total.

A Tabela 08 apresenta a faixa salarial das mulheres no subsetor Administração Pública entre os anos de 2002 e 2011.

Tabela 08 - Faixa Salarial das mulheres no subsetor Administração Pública nos Administração Pública entre os anos de 2002 e 2011 (\%)

\begin{tabular}{ccccccccccc}
\hline $\begin{array}{c}\text { Faixa } \\
\text { Salarial }\end{array}$ & $\mathbf{2 0 0 2}$ & $\mathbf{2 0 0 3}$ & $\mathbf{2 0 0 4}$ & $\mathbf{2 0 0 5}$ & $\mathbf{2 0 0 6}$ & $\mathbf{2 0 0 7}$ & $\mathbf{2 0 0 8}$ & $\mathbf{2 0 0 9}$ & $\mathbf{2 0 1 0}$ & $\mathbf{2 0 1 1}$ \\
\hline $\mathbf{0 , 5}$ a 1 & 0,50 & 0,63 & 0,30 & 0,44 & 1,03 & 1,07 & 1,51 & 2,07 & 1,52 & 1,42 \\
\hline $\mathbf{1}$ a 2 & 26,51 & 29,72 & 32,17 & 32,56 & 37,72 & 36,20 & 34,09 & 29,48 & 32,72 & 27,44 \\
\hline $\mathbf{2}$ a $\mathbf{5}$ & 24,85 & 20,66 & 21,66 & 16,15 & 13,18 & 15,78 & 21,44 & 24,31 & 20,67 & 25,61 \\
\hline $\mathbf{5}$ a 10 & 5,42 & 2,68 & 4,76 & 6,03 & 2,87 & 3,24 & 2,61 & 2,46 & 2,13 & 1,90 \\
\hline $\mathbf{1 0}$ a 20 & 0,80 & 0,94 & 1,27 & 1,39 & 0,64 & 0,72 & 0,55 & 0,60 & 0,59 & 0,71 \\
\hline $\mathbf{+}$ de 20 & 0,27 & 0,23 & 0,36 & 0,23 & 0,06 & 0,04 & 0,04 & 0,06 & 0,02 & 0,07 \\
\hline \{ N class. & 0,07 & 0,33 & 0,05 & 0,05 & 0,78 & 0,61 & 0,76 & 0,57 & 0,81 & 0,70 \\
\hline Total & 58,41 & 55,19 & 60,58 & 56,86 & 56,28 & 57,66 & 61,00 & 59,56 & 58,46 & 57,85 \\
\hline
\end{tabular}

Fonte: RAIS/CAGED, 2011. 
Observa-se que a faixa predominante é entre 1 a 2 salários mínimos, com $26,51 \%$ do total, e em 2011 obteve percentual de 27,44\% seguido da faixa de 2 a 5 salários mínimos, que obteve 24,85\% em 2002 e 25,61\% em 2011.

A Tabela 09 apresenta a faixa salarial dos homens no subsetor Administração Pública do município de Montes Claros/MG entre os anos de 2002 e 2011.

Tabela 09 - Faixa Salarial dos homens no subsetor Administração Pública do município de Montes Claros/MG entre os anos de 2002 e 2011 (\%)

\begin{tabular}{|c|c|c|c|c|c|c|c|c|c|c|}
\hline $\begin{array}{c}\text { Faixa } \\
\text { Salarial }\end{array}$ & 2002 & 2003 & 2004 & 2005 & 2006 & 2007 & 2008 & 2009 & 2010 & 2011 \\
\hline 0,5 a 1 & 0,76 & 1,68 & 0,12 & 0,32 & 1,45 & 1,42 & 1,99 & 1,58 & 1,60 & 2,06 \\
\hline 1 a 2 & 19,15 & 23,18 & 18,94 & 20,59 & 23,64 & 23,17 & 21,48 & 21,27 & 24,16 & 23,57 \\
\hline 2 a 5 & 14,25 & 14,04 & 13,45 & 13,24 & 13,16 & 12,14 & 11,31 & 12,17 & 10,97 & 11,32 \\
\hline 5 a 10 & 4,76 & 3,10 & 4,05 & 5,77 & 3,50 & 3,90 & 2,68 & 3,06 & 2,80 & 2,95 \\
\hline 10 a 20 & 1,54 & 1,51 & 1,67 & 2,36 & 1,20 & 0,95 & 0,90 & 1,73 & 1,35 & 1,49 \\
\hline+ de 20 & 1,08 & 1,11 & 1,15 & 0,84 & 0,33 & 0,29 & 0,25 & 0,27 & 0,19 & 0,26 \\
\hline$\{\tilde{\mathbf{N}}$ class. $\}$ & 0,04 & 0,19 & 0,04 & 0,02 & 0,44 & 0,48 & 0,39 & 0,37 & 0,47 & 0,50 \\
\hline Total & 41,59 & 44,81 & 39,42 & 43,14 & 43,72 & 42,34 & 39,00 & 40,44 & 41,54 & 42,15 \\
\hline
\end{tabular}

Fonte: RAIS/CAGED, 2011.

Os homens tal como as mulheres tem sua maior concentração de trabalhadores nas faixas de remuneração de 1 a 2 salários mínimos com 19,15\% em 2002 e 23,57\% em 2011. A faixa salarial de 2 a 5 salários mínimos sofreu uma queda visto que em 2002 ela era responsável por 14,25\% dos vínculos empregatícios do subsetor Administração Pública e em 2011 era responsável por apenas $11,32 \%$ do total de trabalhadores ocupados no subsetor.

Nas faixas salariais superiores, os homens possuem maior representatividade em relação as mulheres. Observe que na faixa salarial de 5 a 10 salários mínimos as mulheres possuem representatividade de 1,9\%, enquanto os homens 2,95\%. Já a faixa de 10 a 20 salários, as mulheres têm o percentual de $0,71 \%$, enquanto os homens possuem 1,49\% de participação. A faixa de mais de 20 salários mínimos, as mulheres têm $0,07 \%$ de participação, enquanto os homens possuem $0,26 \%$ de representatividade.

O Gráfico 03 apresenta a representatividade da faixa salarial do total de trabalhadores masculinos e femininos ocupados no subsetor Administração Pública do município de Montes Claros/MG entre os anos de 2002 e 2011. 
Gráfico 03 - Representatividade da faixa salarial do total de trabalhadores masculinos e femininos ocupados no subsetor Administração Pública do município de Montes Claros/MG entre os anos de 2002 e 2011

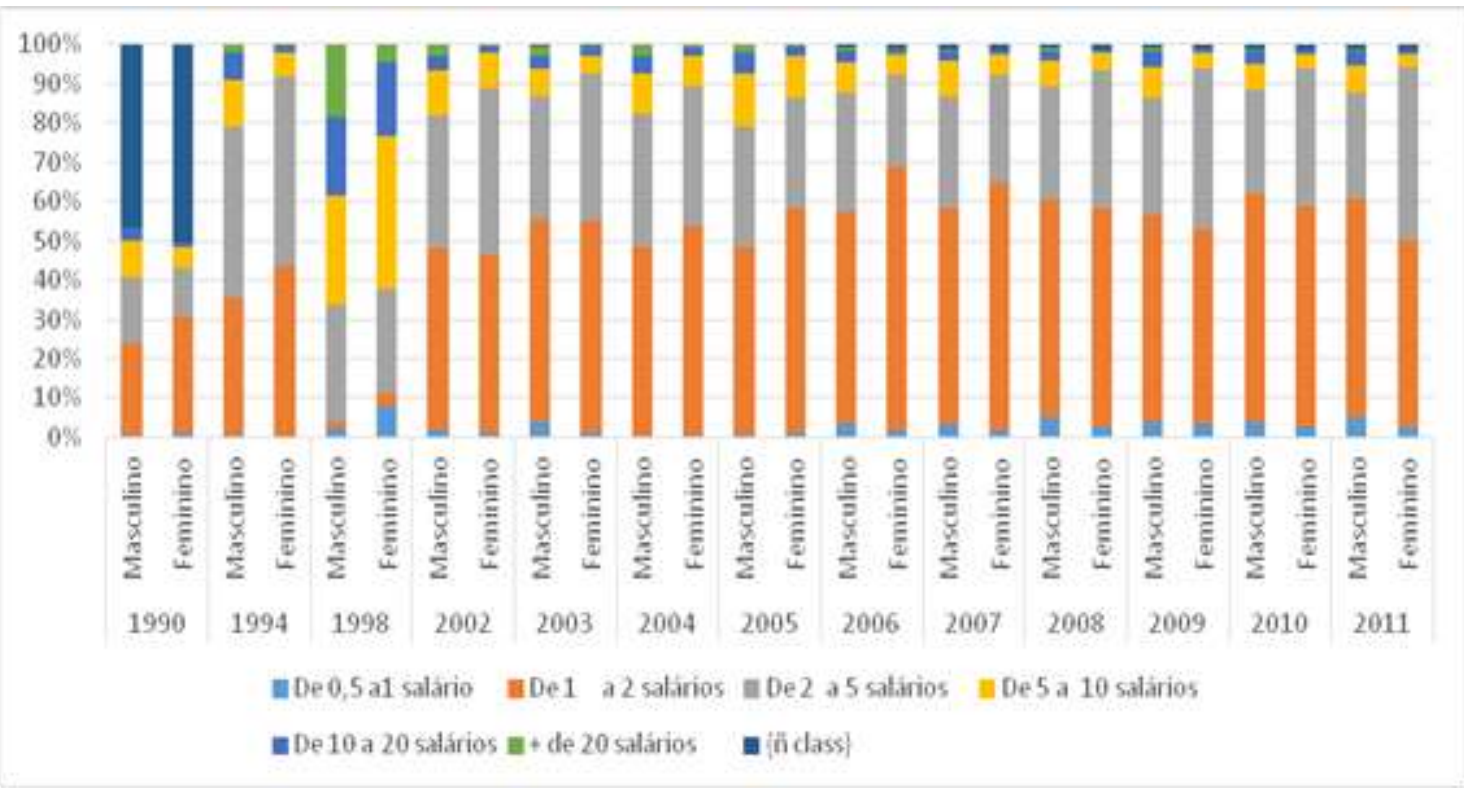

Fonte: RAIS/CAGED, 2011.

Ao analisar os dados sobre os trabalhadores ocupados no subsetor Administração Pública, em relação a teoria da segmentação pode-se constatar que em relação ao gênero existem diferenças, onde tomaremos como base o ano de 2011, sendo assim:

Mesmo com aumento do nível de escolaridade das mulheres ao longo do período estudado, pode-se constatar que elas continuam recebendo remuneração diferenciada em relação aos homens. Onde no ano de 2011 as mulheres representavam $41,10 \%$ do total de trabalhadores possuindo o ensino superior, e os homens sendo representados por $23,06 \%$ do total de trabalhadores, podendo assim fazer a leitura dos dados notou-se que os salários superiores a 5 salários mínimos no subsetor Administração Pública são representados em grande parte pelo sexo masculino. Demonstrando assim que apesar do percentual de mulheres com grau de instrução maior em relação ao percentual de homens, tem-se o sexo masculino mais bem remunerado independente do seu nível de escolaridade.

A teoria da segmentação comprova que há a existência de vários mercados, onde a remuneração e dada de forma diferente, sendo assim o salário pago aos trabalhadores variará de acordo com os critérios do mercado, empresa ou setor. Onde no subsetor Administração Pública pode-se comprovar que a relação gênero salario é uma característica relevante. 


\section{CONSIDERAÇÕES FINAIS}

Este estudo teve por objetivo geral analisar as características dos trabalhadores do nível operacional do subsetor Administração Pública do município de Montes Claros/MG. Este objetivo foi atingido, visto que foram apresentadas analises das características dos trabalhadores de nível operacional do subsetor Administração Pública do município de Montes Claros/MG, tomando como base a escolaridade, a faixa etária e a faixa salarial (remuneração) dos mesmos.

O objetivo especifico 01 (analisar os dados do mercado de trabalho do subsetor Administração Pública do município de Montes Claros/MG) foi alcançado, posto que, o o tópico 4, análise e discussão de dados, analisou os dados do subsetor Administração Pública do município de Montes Claros/MG.

O objetivo especifico 02 (apresentar conceitos e classificações de mercado de trabalho, setor de serviços e subsetor Administração Pública) foi atingido, visto que, o tópico 2, referencial teórico, apresentou conceitos e classificações de mercado de trabalho, setor de serviços e subsetor Administração Pública.

O objetivo especifico 03 (discorrer sobre escolaridade (grau de instrução), representatividade de gênero, faixa etária e faixa salarial dos trabalhadores do município de Montes Claros/MG) foi alcançado, posto que, os tópicos 2 e 4 abordaram o mercado de trabalho e suas variáveis escolaridade, representatividade de gênero, faixa etária e faixa salarial tanto em planos gerais, como especificamente o município de Montes Claros/MG.

O objetivo especifico 04 (descrever o subsetor Administração Pública do município de Montes Claros/MG) foi atingido, visto que, o tópico 4 traçou o perfil do subsetor Administração Pública do município de Montes Claros/MG entre os anos de 2002 e 2011.

A partir do estudo realizado pode-se observar que no subsetor Administração Pública há uma participação maior das mulheres com maior nível de escolaridade e menor remuneração. A teoria da segmentação considera que a compreensão sobre mercado de trabalho envolve diferentes mercados, neste caso identifica-se diferenças quanto ao gênero.

Os trabalhadores desse subsetor em sua maior parte estão localizados no Grupo 3 representados pelos trabalhadores com ensino superior, tendo sua maior representatividade na faixa etária dos 40 a 49 anos e recebendo em média cerca de 
Renan Zorzy dos Santos Cardoso; Éder de Souza Beirão; Roney Versiani Sindeaux; Simone Viana Duarte.

1 a 2 salários mínimos. É valido ressaltar que o presente artigo não aborda os trabalhadores a nível de gestores, consequentemente para se agregar valor ao tema, recomenda-se somar aos resultados obtidos as características dos gestores do setor administração pública.

O objetivo do presente artigo relaciona os resultados obtidos a partir dos dados coletados e analisados do subsetor Administração Pública. Contudo o estudo deve ser comparado aos demais subsetores pertencentes ao setor administração pública, ressaltando assim as características marcantes dos trabalhadores de cada subsetor, que com base na teoria da segmentação permitirão a compreensão da situação desses mercados de trabalho.

\section{REFERÊNCIAS}

ALBRECHT, Karl. Revolução nos Serviços: como as empresas podem revolucionar a maneira de tratar os seus clientes. São Paulo: Pioneira, 2000.

ANTUNES, Ricardo. Os Sentidos do Trabalho: ensaio sobre a afirmação e a negação do trabalho. 6. ed. São Paulo: Boitempo Editorial, 2003.

CERVO, Amado L.; BERVIAN, Pedro A.; SILVA, Roberto da. Metodologia Científica. 6. ed. São Paulo: Pearson Prentice Hall, 2007.

COBRA, Marcos. Marketing de Serviços: Conceitos e estratégias. São Paulo: McGrawwHill, 1986.

CUNHA, Paulo Vieira da. A Organização dos Mercados de Trabalho: três conceitos alternativos. Revista de Administração de Empresas, v. 19, n. 1, p. 29-46, jan./mar. 1979.

FITZSIMMONS, James; FITZSIMMONS, Mona. Administração de Serviços: operações, estratégia e tecnologia da informação. 2.ed. Porto Alegre: Bookman, 2000.

GAMBIER, Dominique; VERNIERES, Michel. Le marché du travail. Paris: Econômica, 1991.

GIL, Antônio Carlos. Como Elaborar Projetos de Pesquisa. 4. ed. São Paulo: Atlas, 2002.

GRÕNROOS, Christian. Marketing: gerenciamento e serviços: a competição por serviços na hora da verdade. Rio de Janeiro: Campus, 1995.

KOTLER, Philip. Administração de Marketing: análise, planejamento, implementação e controle. 4.ed. São Paulo: Atlas, 1994. 
MAUAD, L. G. A.; PAMPLONA, E. O. ABC/ABM e BSC: Como essas ferramentas podem se tornar poderosas aliadas dos tomadores de decisão das empresas. In: CONGRESSO INTERNACIONAL DE COSTOS, VIII, 2003. Disponível em <http://www.iem.efei.br/edson/download/Artguilaconginter03.pdf> Acesso em: 02 de abril de 2017.

OLIVEIRA, Sidinei Rocha de; PUCCININI, Valmiria Carolina. Mercado de Trabalho: múltiplos (des)ententimentos. Revista de Administração Pública. Rio de Janeiro 45(5):1517-538, Set./out. 2011. Disponível em:

$<$ http://www.scielo.br/pdf/rap/v45n5/v45n5a12.pdf> Acesso em: 04 de Novembro de 2017.

RICHARDSON, Roberto Jarry. Pesquisa Social: métodos e técnicas. 3.ed. São Paulo: Atlas, 1999.

SYSTEM OF NATIONAL ACCOUNT 1993. [Rev. ed.]. Brussels/Luxemburg: Commission of the European Communities; Washington, D.C.: International Monetary Fund; Paris: Organisation for Economic Co-operation and Development; New York: United Nations; Washington, D.C.: World Bank, 1993. Disponível em: $<$ https://unstats.un.org/unsd/nationalaccount/docs/1993sna.pdf > Acesso em: 04 de Novembro de 2017.

Recebido em: abril de 2018

Aceito em: dezembro de 2018 